\title{
Design of Playful Authoring Tools for Social and Behavioral Science
}

\section{Casper Harteveld}

Northeastern University

c.harteveld@northeastern.edu

Nolan Manning

Northeastern University

manning.n@husky.neu.edu

Farah Abu-Arja

Northeastern University

abu-arja.f@husky.neu.edu

\section{Rick Menasce}

Northeastern University

menasce.r@husky.neu.edu
Dean Thurston

Northeastern University

thurston.d@husky.neu.edu

Gillian Smith

Northeastern University

gi.smith@northeastern.edu

Steven C. Sutherland

University of Houston-Clear Lake sutherland@uhcl.edu

Permission to make digital or hard copies of part or all of this work for personal or classroom use is granted without fee provided that copies are not made or distributed for profit or commercial advantage and that copies bear this notice and the full citation on the first page. Copyrights for third-party components of this work must be honored. For all other uses, contact the owner/author(s).

Copyright held by the owner/author(s).

IUl'17 Companion, March 13-16, 2017, Limassol, Cyprus

ACM 978-1-4503-4893-5/17/03.

http://dx.doi.org/10.1145/3030024.304098

Abstract

Playful environments are increasingly being used for conducting research. This makes a game platform for authoring research studies and teaching about how to conduct research a necessary progression. In this paper, we discuss Mad Science, a playful platform that is being created to allow users to create behavioral experiments. We discuss iterations of the authoring tools, including lessons learned, and the need for $\mathrm{Al}$ assistance to guide and teach users.

\section{Author Keywords}

authoring tools; playful; experiments; interface design.

\section{ACM Classification Keywords}

H.5.m. [Information Interfaces and Presentation (e.g. HCl)]:

Miscellaneous; I.6.8. [Simulation and Modeling]: Types of

Simulation-Gaming

\section{Introduction}

Playful environments are increasingly used as research environments [2], specifically for social and behavioral science research. Clear affordances that games and other playful environments offer for research are to: (a) immerse people in authentic situations, including situations that are difficult to observe in reality; (b) retrieve behavioral data in an unobtrusive but controlled manner; and (c) engage a global audience over a sustained period of time. Despite that there 


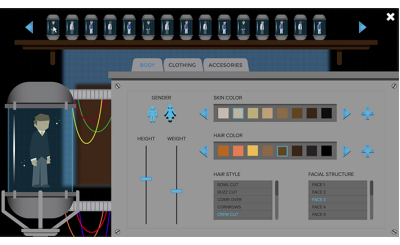

Figure 1: Initial character creator (c) Northeastern University.

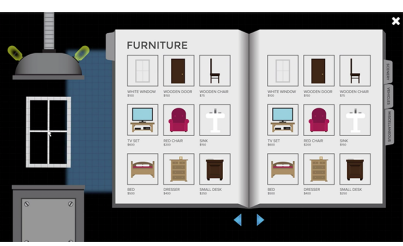

Figure 2: Initial scene creator. (C) Northeastern University.

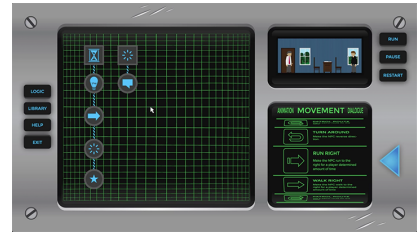

Figure 3: Initial scriptor. (C) Northeastern University.

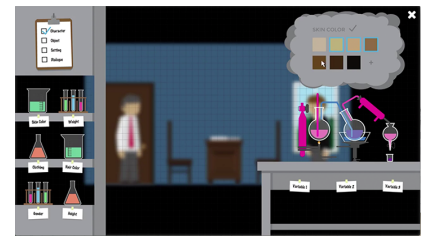

Figure 4: Initial manipulator. (C) Northeastern University. are valid concerns about the validity of such research, research thus far shows that, for the most part, individuals behave similarly in both virtual and real environments [1].

Apart from methodological concerns, to foster a paradigm shift technology is needed to empower researchers to perform virtual (playful) research. Various software does exist to create virtual experiments, such as E-Prime [4]. However, such software often lacks a user friendly interface, does not teach its users about research, and does not facilitate the creation of gamified experiments. Our aim is to enable the next generation of virtual experiments, which are easy to create and harness the affordances of play.

To this end, we have been building a unique playful platform called Mad Science [5]. This platform provides users with authoring tools to construct a virtual theatre, using a library of props and content, to perform scientific exploration with game-like virtual scenarios. We have been designing this as a playful platform, promoting a user experience that is pleasurable and goes beyond utilitarian work and task contexts, and making it accessible to users with no technical or artistic skills. In this paper we present the design process of our authoring tools thus far by reflecting on the various interface designs and what future needs exist.

\section{The Authoring Tools}

The Mad Science platform consists of authoring tools to create experiments and a website portal to disseminate these. ${ }^{1}$ It is intended to be used in higher education for teaching experimental research in an constructionist, experiential manner and by professional researchers for conducting the next generation of experimental research. When users sign up as "mad scientist", they are given a set of

\footnotetext{
${ }^{1}$ https://web.northeastern.edu/madscience/
}

tools to create playable experimental scenarios, which immerse players into 2D narrative based situations where they need to make decisions. To illustrate how the basic tools work we present an example use scenario, in which a user named "Kate" wants to create an experiment to explore how courtroom factors impact self-representation.

Kate first uses the character creator to design the playercharacter and the non-player characters. The scenario will be based in a court and so Kate would like to have characters that are typically present in a courtroom setting. Some of these characters already exist; she selects them from the art asset library and makes some minor adjustments. For the plaintiff and judge, no character exists and she creates them by modifying basic templates.

She then moves to the scene creator, which allows her to select or modify an existing setting, or create an entirely new setting from scratch. The tool acts much like a theater stage where users can select a background and objects, including characters, by picking them from a list of objects. Kate selects a bench for the judge, a witness stand, and tables for the plaintiff and defendant, and then positions them appropriately on the basic background she picked.

She continues with the scriptor. With this tool, she can make a visual decision tree for how her scenario unfolds and specify the dialog and actions (e.g., sounds, movements) as well as how performance is evaluated (through variables and if/then statements). Kate creates a script where the plaintiff argues that the defendant owes her money for a car repair and the defendant needs to crossexamine and provide evidence that he paid what they agreed upon. She creates a confidence variable that increases or decreases in how well players play the role of defendant.

From here Kate enters the manipulator. With this tool, users 


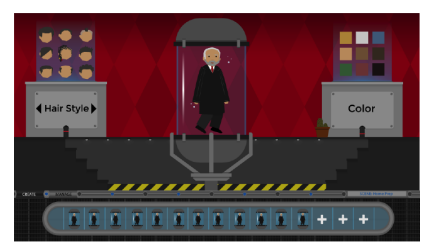

Figure 5: Revised character creator. (c) Northeastern University.

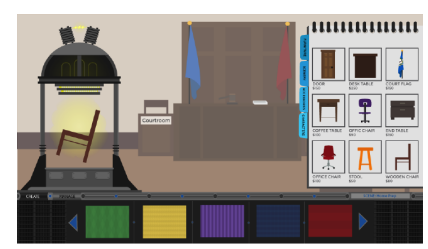

Figure 6: Revised scene creator. (C) Northeastern University.

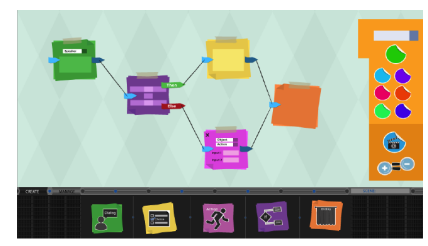

Figure 7: Revised scriptor. (c) Northeastern University.

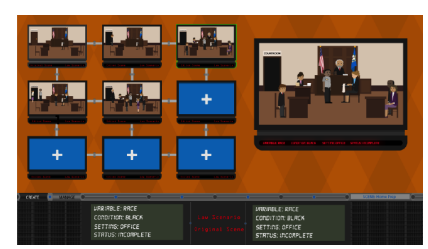

Figure 8: Revised manipulator. (C) Northeastern University. can make scenario variations by changing text, characters, setting, or a combination thereof. She declares in the manipulator that she would like to see how different judge types (independent variable) influence player confidence (dependent variable). Kate declares that there are two kinds of judges, a "facilitative" and "business-like" judge. She is prompted for which condition the original scenario satisfies, then edits the copy for the second condition, while the tool registers the differences between original and copy.

\section{Interface Design}

The aforementioned functionality of the four basic authoring tools has largely remained the same over time. Their interface, however, has drastically changed based on user feedback. Here we discuss the three major designs: the original, revised, and current interface.

\section{Original Interface}

For the original interface design (Fig. 1 to Fig. 4), we took inspiration from various scientific disciplines: biology for the character creator, physics for the scene creator, computer science for the scriptor, and chemistry for the manipulator. We aspired making it playful through interacting with symbolic objects for creation, such as using beakers to manipulate variables and a futuristic 3D printer for decorating the scenes. In terms of style, the visualizations stem from the dark art of alchemy with its black canvas and other dark colors. Users can access a hidden menu to navigate between the tools. The main critique from testing with a mockup video was that there was little coherency between the tools except for the science-y and alchemy themes. Questions were also raised about the usability.

\section{Revised Interface}

In our revision, we abandoned the science-y and alchemy themes (Fig. 5 to Fig. 8). We made the interface more col- orful and incorporated a similar background pattern and a menu panel to make the various tools more coherent. However, we aimed to preserve the playfulness and kept some elements from the previous interface, such as the futuristic 3D printer. We did ensure that these playful elements would take up less screen space compared to the original version, enabling more work space and a cleaner interface. The character and scene creator remained roughly the same; the scriptor and manipulator were completely overhauled. For the scriptor, we were inspired by Twine [3] and postits on a whiteboard for brainstorming. For the manipulator, we thought of PowerPoint's master template and a security camera room, where each monitor represents a copy of the master with one or more manipulations.

We developed prototypes of two tools: the scene creator and the scriptor. With these two tools, users can develop complete scenarios because characters are included as objects in the scenario creator and users can simply load an existing scenario and make the necessary changes for an alternative condition. Although users were generally positive, the main complaint was that the tools were cumbersome for extensive use and not intuitive. The work space was still too restricted and playful elements such as the 3D printer delayed the creation process too much.

\section{Current Interface}

The continued critique on usability led to the current design (Fig. 9 to Fig. 12). This time we took inspiration from existing tools, such as Adobe Illustrator, and made sure the work space is almost the entire screen by enabling the possibility of hiding interface elements. We removed the playful elements but retained a playful feel through the interface aesthetics. We tested the current interface design on various occasions. From these tests it became apparent that users were able to use the tools with little to no instruction. 


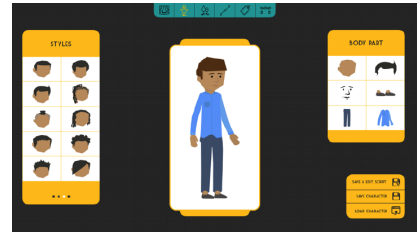

Figure 9: Current character creator. (c) Northeastern University.

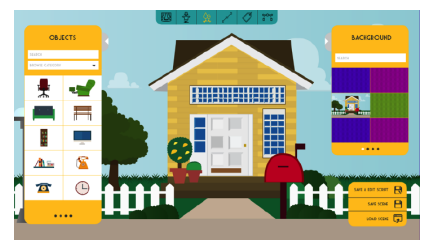

Figure 10: Current scene creator (C) Northeastern University.

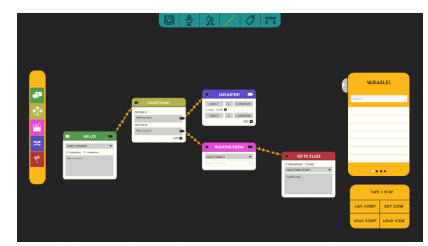

Figure 11: Current scriptor. (C) Northeastern University.

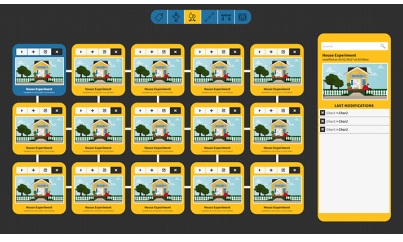

Figure 12: Current manipulator (c) Northeastern University.

\section{The Need for Intelligence}

Another important observation while testing the tools is that users did not necessarily create experiments. In fact, one of the issues thus far in our research is that users do not understand the concept of the independent variable and the need for creating alternative conditions-despite prior instructions. Similarly, deciding on how to evaluate the experiment by means of a dependent variable is equally hard. Another problem is that users tend to create scenarios from scratch rather than making use of existing content or verifying whether their idea has already been tried. Therefore, users seem to have trouble with all facets of experiment creation-hypothesis generation, hypothesis testing, and random assignment. The complete development of the tools, in particular the addition of the manipulator, will help to scaffold the process of experiment creation better. However, we expect that the inclusion of Artificial Intelligence (Al) assistance is necessary for successful educational use. Of course, similar to our process of finding a balance between usability and playfulness, it will be finding a balance between autonomy and (Al-assisted) support.

\section{Conclusion}

In this paper we presented the design of the authoring tools of a platform called Mad Science, which aims to provide a playful way to advance the social and behavorial sciences. Notable from this design process is that with each iteration we moved farther away from the original playful intention and focused more on the usability of the tools. When it comes to the tools, productivity is crucial and playful elements may end up making the experience more frustrating than engaging. In fact, the current design is only aesthetically playful. All mechanical playfulness has been removed. This does not mean that playfulness should be avoided; rather, we think that playfulness should be sought in what the platform represents and what designers create. We conceive of a "mad scientist" as someone who is intrinsically curious and makes use of inventive and playful ways to explore human behavior, and using the tools in that manner is what makes it playful, not the interface design of the tools themselves. Further iteration is still needed because another insight is a need for Al-assisted support. Most users seemed to fail to accomplish the basics of experiment creation, despite prior instruction. Future effort will involve finding the appropriate design to include this support.

\section{Acknowledgements}

We thank everyone who contributed to the design of the authoring tools. We further acknowledge the grant support from Northeastern University, Legal Services Corporation (LSC-TIG \#14035), and DARPA (D16AP0011).

\section{REFERENCES}

1. Jim Blascovich and Jeremy Bailenson. 2011. Infinite reality: Avatars, eternal life, new worlds, and the dawn of the virtual revolution. HarperCollins, New York, NY.

2. Eduardo Calvillo-Gámez, Jeremy Gow, and Paul Cairns. 2011. Introduction to special issue: Video games as research instruments. Entertainment Computing 2, 1 (2011), 1-2.

3. Chris Klimas. 2009. Twine: An open-source tool for telling interactive, nonlinear stories. (2009). http://twinery.org/

4. Walter Schneider, Amy Eschman, and Anthony Zuccolotto. 2002. E-Prime: User's guide. Psychology Software Incorporated.

5. Steven C. Sutherland, Casper Harteveld, Gillian Smith Joseph Schwartz, and Cigdem Talgar. 2015. Exploring digital games as a research and educational platform for replicating experiments. In NEDSI Conference. Boston, MA. 